\title{
REVISED Human aldose reductase unfolds through an
}

\section{intermediate [version 2; peer review: 1 approved, 2 approved}

\section{with reservations]}

\author{
Gurprit Sekhon, Ranvir Singh (ib) \\ Department cum National Center for Human Genome Studies and Research, Panjab University, Chandigarh, 160014, India
}

V2 First published: 26 Apr 2019, 8:564

https://doi.org/10.12688/f1000research.18963.1

Latest published: 05 Nov 2019, 8:564

https://doi.org/10.12688/f1000research.18963.2

\section{Abstract}

Background: Human aldose reductase (hAR) is the first and ratelimiting enzyme of the polyol pathway. For the development of secondary complications of diabetes in chronic hyperglycemic conditions, one of the critical factors is the increased flux of glucose through the polyol pathway. Due to this clinical implication, hAR attracted considerable attention from the drug discovery perspective. In spite of extensive characterization in the context of biochemical and structural aspects, we know very little about the unfolding behavior of hAR. This study reports equilibrium unfolding studies of hAR.

Methods: We carried out thermal denaturation and chemical-induced equilibrium unfolding studies of hAR monitored by circular dichroism and fluorescence spectroscopy.

Results: Thermal denaturation studies presented a classical picture of two-state unfolding from native to the denatured state. The data was used to derive thermodynamic parameters and study the thermostability of hAR. Chemical induced equilibrium unfolding studies led us to discover an intermediate state, which gets populated at 3.5-4.0 $\mathrm{M}$ and 0.7-2.0 $\mathrm{M}$ of urea and $\mathrm{GuHCl}$, respectively.

Thermodynamic parameters derived from chemical-induced unfolding are in agreement with those obtained from thermal denaturation of hAR.

Conclusion: This study revealed that aldose reductase unfolds from native to the unfolded state via an intermediate. Assessment of the thermodynamic stability of native, intermediate, and unfolded states shows that significant energy barriers separate these states, which ensures the cooperativity of unfolding. As hAR functions in cells that are under osmotic and oxidative stress, these in vitro findings may have implications for its native conformation under the physiological state.
Open Peer Review

Approval Status ? ?

12

23

version 2

(revision) ?

05 Nov 2019

version 1

26 Apr 2019

view

view

1. Jonathan W. Mueller (iD), University of Birmingham, Birmingham, UK

2. Vladimir Uversky ${ }^{D}$, University of South Florida, Tampa, USA

3. Yong-Bin Yan ID), Tsinghua University, Beijing, China

Any reports and responses or comments on the article can be found at the end of the article. 


\section{Keywords}

Aldose reductase, Protein unfolding, Folding intermediate, Cooperativity, Tryptophan fluorescence, ANS fluorescence, Thermal denaturation

Corresponding author: Ranvir Singh (ranvir1@pu.ac.in)

Author roles: Sekhon G: Data Curation, Formal Analysis, Writing - Original Draft Preparation; Singh R: Conceptualization, Supervision, Writing - Review \& Editing

Competing interests: No competing interests were disclosed.

Grant information: The author(s) declared that no grants were involved in supporting this work.

Copyright: $\odot 2019$ Sekhon G and Singh R. This is an open access article distributed under the terms of the Creative Commons Attribution License, which permits unrestricted use, distribution, and reproduction in any medium, provided the original work is properly cited.

How to cite this article: Sekhon G and Singh R. Human aldose reductase unfolds through an intermediate [version 2; peer review:

1 approved, 2 approved with reservations] F1000Research 2019, 8:564 https://doi.org/10.12688/f1000research.18963.2

First published: 26 Apr 2019, 8:564 https://doi.org/10.12688/f1000research.18963.1 


\section{REVISED Amendments from Version 1}

We are thankful to the reviewers for their valuable comments. In response to the comments, we have changed the manuscript.

The followings are significant changes from the previous version of the manuscript.

1. We have included additional references and have stressed the relevance of the study.

2. Figures have been revised as per suggestion by the

reviewer(s).

3. The word 'thermal unfolding' has been replaced by 'thermal denaturation.'

4. We have gone through the manuscript carefully and have made necessary changes regarding linguistic issues.

Any further responses from the reviewers can be found at the end of the article

\section{Abbreviations}

GuHCl, guanidine hydrochloride; TCEP, (tris(2carboxyethyl)phosphine); ANS, 8-anilino-1-naphthalenesulfonic acid ammonium salt; IPTG, isopropyl $\beta$-D-1-thiogalactopyranoside; Trp, tryptophan.

\section{Introduction}

Human aldose reductase (hAR) (EC 1.1.1.21) is an NADPHdependent oxidoreductase that belongs to the superfamily of aldo-keto reductases ${ }^{1}$. hAR is the first and rate-limiting enzyme of the polyol pathway and converts glucose to sorbitol $^{2}$. The polyol pathway is up-regulated under hyperglycemic conditions, and a significant proportion of glucose gets fluxed through this pathway, which leads to the accumulation of sorbitol, consumption of NADPH, and redox imbalance of $\mathrm{NADPH} / \mathrm{NADP}^{+}$ratio. All these factors have been linked with various tissue-based pathologies associated with secondary complications of diabetes mellitus ${ }^{3}$. Due to its clinical importance from the perspective of developing potent inhibitors to prevent or delay the onset of secondary diabetic complications, hAR has been widely studied in almost every aspect ${ }^{4}$.

Extensive information is available in the literature about the structure and function of hAR, mainly related to active site of hAR from high-resolution crystal structures with a number of potential inhibitors ${ }^{5}$, flexibility in the hAR binding site pocket ${ }^{6}$ and the thermodynamics of closing/opening of the specificity pocket within binding site pocket of $\mathrm{hAR}^{7}$. There is little investigation related to the folding/unfolding mechanism of hAR.

Protein folding is a fundamental process in all living systems. The linear sequence of amino acids encodes the information required for a polypeptide to fold. Despite extensive research and progress made over the years to understand this fundamental process, a complete understanding of protein folding mechanism(s) and the folding code remains elusive ${ }^{8}$. Various models have been proposed to explain the mechanism underlying protein folding reaction from time to time'. 'New view folding model' based on energy landscape theory (ELT) and 'defined pathways model' based on the concept of foldons are current alternatives to explain the protein folding mechanism. ${ }^{10}$.
Among several hallmarks of protein folding are its spontaneity and cooperativity, along with fast reaction timescale. Usually, a small free energy change is required to shift the equilibrium between the folded and unfolded state ensemble. Complex cellular solvation environment plays a vital role in regulating the equilibrium between folded and unfolded ensemble in vivo, which are separated by small free energy barrier $(\sim 5 \text { - } 10 \text { Kcal mol-1 })^{11}$.

Under physiological conditions, protein structure fluctuates among different native conformations separated by close free energy barriers ${ }^{12}$. Since hAR activity leads to sorbitol accumulation, leading to osmotic stress, it seems to function under stress conditions which might perturb its native conformation ensemble. Here we report on thermal denaturation and chemical induced unfolding studies of hAR. Thermal denaturation revealed a simple two-state transition, whereas chemical induced unfolding led us to discover an intermediate state during hAR unfolding.

\section{Methods}

Materials

All chemicals were reagent grade and purchased from Sigma-Aldrich.

\section{Protein purification}

The hAR cDNA cloned into expression vector pET-15b (Novagen) was a kind gift from Dr. Alberto Podjarny (Department of Integrated Structural Biology, Institut de Génétique et de Biologie Moléculaire et Cellulaire, CNRS, INSERM, France). The plasmid, coding for a hexahistidine-tagged protein, was expressed into $E$. coli strain BL21 (DE3) (Novagen). The cells with recombinant plasmid were grown with $100 \mu \mathrm{M}$ ampicillin at $37^{\circ} \mathrm{C}$ to an $\mathrm{OD}_{600} \mathrm{~nm}$ value of 0.7 , and protein expression was induced by adding $1 \mathrm{mM}$ IPTG. Cells were grown for a further 3 hours at $37^{\circ} \mathrm{C}$. All further operations were carried out at $4^{\circ} \mathrm{C}$ unless otherwise stated. Cells were centrifuged, resuspended, and lysed by sonication. A Ni-NTA affinity column (GE Healthcare) was used for protein purification. The material used for the stationary phase for the column was Ni-Sepharose, and the flow rate of the column was adjusted to $0.5 \mathrm{ml} \mathrm{min}{ }^{-1}$. Imidazole and other salts were removed by repeated dialysis in $50 \mathrm{mM}$ potassium phosphate, $\mathrm{pH}-7$ buffer containing $50 \mathrm{mM} \mathrm{NaCl}$. Protein concentration was estimated using the molar extinction coefficient and absorbance reading at 280 $\mathrm{nm}$. The histidine tag from recombinant protein was removed by thrombin (4 units of thrombin per $\mathrm{mg}$ of recombinant protein at room temperature for 3 hours). The cleaved protein was passed through the Ni-NTA column, and purified protein without tag was collected as flow-through. Enzyme activity was checked as per standard assay ${ }^{13}$. We analyzed the homogeneity and molecular weight of hAR with and without histidine tags under denaturing conditions on $15 \%$ SDS-PAGE. Purified hAR was stored at $-20^{\circ} \mathrm{C}$ for further studies.

\section{Thermal denaturation}

Thermal denaturation was carried out at a final concentration of $2.8 \mu \mathrm{M}$ protein in $50 \mathrm{mM}$ potassium phosphate buffer, $\mathrm{pH} 7.0$, containing $50 \mathrm{mM} \mathrm{NaCl}$ and $0.1 \mathrm{mM}$ TCEP. The transition between $20-70{ }^{\circ} \mathrm{C}$ was followed using a far-UV circular 
dichroism (CD) signal at $222 \mathrm{~nm}$ by using a $0.1 \mathrm{~cm}$ path-length cuvette at a sampling rate of $1.0{ }^{\circ} \mathrm{C} \mathrm{min}-1$ in a Jasco J-810 spectropolarimeter. After subtracting buffer blank, we have reported the change in ellipticity (millidegree) at $222 \mathrm{~nm}$.

\section{Chemical induced unfolding}

To follow chemical induced unfolding, we prepared samples with $1.4 \mu \mathrm{M}$ protein concentration in phosphate buffer (described earlier), containing different concentrations of $\mathrm{GuHCl} /$ urea. Samples were incubated for 12 hours to reach equilibrium at $25^{\circ} \mathrm{C}$, after which no change in signal occurred either in fluorescence or CD spectra. Trp fluorescence (excitation at $295 \mathrm{~nm}$ and emission recorded between $300 \mathrm{~nm}$ to $400 \mathrm{~nm}$ ) and ANS fluorescence (excitation at $370 \mathrm{~nm}$ and emission recorded between $400 \mathrm{~nm}$ to $600 \mathrm{~nm}$ ) measurements were performed using a Hitachi F-7000 fluorescence spectrophotometer for $\mathrm{GuHCl}$ samples and Jasco J-815 spectropolarimeter for urea samples. Far-UV CD measurements were performed using Jasco J-810 spectropolarimeter for $\mathrm{GuHCl}$ samples and Jasco J-815 spectropolarimeter for urea samples. Quartz cuvette of $1 \mathrm{~cm}$ and $0.5 \mathrm{~cm}$ path-length were used for fluorescence and CD measurements, respectively. All measurements were done at $25{ }^{\circ} \mathrm{C}$. We have reported spectra as ellipticity (millidegree) after baseline correction.

\section{Heat capacity change $\left(\Delta C_{p}\right)$ calculations}

We have calculated the value of $\Delta C_{p}$ for the unfolding of hAR from the change in accessible surface area ( $\triangle \mathrm{ASA}$ ) according to Equation $1^{14}$

$$
\Delta C_{p}=-251+0.19 \times[\Delta \mathrm{ASA}]
$$

(Equation 1)

ProtSA webserver was used to calculate the change in accessible surface area from native to the unfolded conformation of hAR ${ }^{15}$.

\section{Data analysis}

GraphPad Prism version 7.04 for Windows (GraphPad Software, La Jolla, California) was used for the analysis of thermal denaturation and chemical-induced unfolding data based on two-state and three-state models respectively, as described in following sections.

\section{Thermal denaturation}

The Least-square analysis was used to fit the data to Equation $2^{16}$.

$$
Y=\frac{\left(A_{n}+b_{N} \times T\right)+\left(A_{u}+b_{U} \times T\right) \times \exp \left(\left(\frac{\Delta H_{g}}{R}\right) \times\left(\frac{1}{T_{g}}-\frac{1}{T}\right)\right)}{1+\exp \left(\left(\frac{\Delta H_{g}}{R}\right) \times\left(\frac{1}{T_{g}}-\frac{1}{T}\right)\right)}
$$

Where $A_{n}$ and $A_{u}$ are native and unfolded state baseline intercepts, respectively, and $b_{N}$ and $b_{U}$ are native and unfolded baseline slopes, respectively. $\Delta H_{m}$ is enthalpy change at melting temperature $\left(T_{g}\right) . T$ is absolute temperature, and $\mathrm{R}$ is the gas constant.
Calculation of $\Delta G$ values for the transition region

Signal for native $\left(Y_{N}=A_{n}+b_{N} \times T\right)$ and unfolded baseline $\left(Y_{U}=A_{u}+b_{U} \times T\right)$ for every point in transition region was calculated from Equation 2. If $Y$ is signal for a particular point in transition region, then the fraction of unfolded protein $\left(F_{u}\right)$ at this point is given by Equation 3.

$F_{u}=\frac{Y_{n}-Y}{Y_{n}-Y_{u}}$

(Equation 3)

The equilibrium constant $(\mathrm{k})$ was calculated from the relative population of species using Equation 4.

$k=\frac{F_{u}}{1-F_{u}}$

(Equation 4)

$\Delta G$ was calculated as a function of temperature using Equation 5.

$$
\Delta G=-\mathrm{R} T \ln k
$$

(Equation 5)

Thermal stability curve

The thermal stability curve of hAR was constructed based on Equation 6-8 $8^{17}$.

$$
\begin{array}{ll}
\Delta H_{T}=\Delta H_{g}+\Delta C_{p}\left(T-T_{g}\right) & \text { (Equation 6) } \\
\Delta S_{T}=\frac{\Delta H_{g}}{T_{g}}+\Delta C_{p} \times L N\left(\frac{T}{T_{g}}\right) & \text { (Equation 7) } \\
\Delta G_{s}=\Delta H_{g} \times\left(1-\frac{T}{T_{g}}\right)+\Delta C_{p} \times\left(T-T_{g}-\left(T \times L N\left(\frac{T}{T_{g}}\right)\right)\right) & \text { (Equation 8) }
\end{array}
$$

Where $\Delta H_{T}$ and $\Delta S_{T}$ are enthalpy change and entropy change, respectively, at temperature $T$ with reference to $T_{g} . T_{h}, T_{s}$ and $T_{g}$ are the temperatures at which $\Delta H, \Delta S$, and $\Delta G$ are zero, respectively. $\Delta G_{s}$ is the stabilization free energy of the native state relative to the unfolded state.

\section{Chemical induced unfolding}

The least-square analysis was used to fit the data to Equation $9^{16}$.

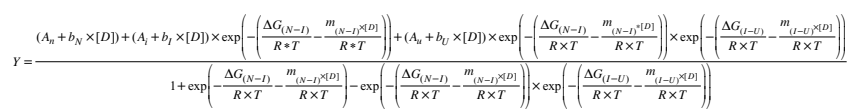

(Equation 9)

Where $A_{n}, A_{u}$, and $A_{i}$ are the native, unfolded, and intermediate baseline intercepts, respectively, and $\mathrm{b}_{\mathrm{N}}, b_{U}$, and $b_{I}$ are the native, unfolded, and intermediate baseline slopes, respectively. $[D]$ is denaturant concentration in a molar unit. $m_{(N-I)}$ and $m_{(I-U)}$ are denaturant gradient for native to intermediate and intermediate to unfolded state, respectively. $\Delta G_{(N-I)}$ and $\Delta G_{(I-U)}$ are stabilization free energy of intermediate state relative to the native and unfolded state, respectively. 


\section{Results}

Thermal denaturation monitored by far-UV CD

Change in ellipticity at $222 \mathrm{~nm}$ fitted well based on a two-state model (Figure 1A). This analysis gave values for $\Delta H_{g}$ and $T_{g}$, which along with the $\Delta C_{p}$ value calculated from Equation 1 were used for non-linear regression of the transition region $\left( \pm 5 \mathrm{~kJ} \mathrm{~mol}^{-1}\right)$ to Equation 8 (Figure $1 \mathrm{C}$ ). Values of $\Delta H$ and $\Delta S$ were calculated over an extended range of temperatures by using Equation 7 and Equation 8, respectively (Figure 1D). The thermal stability curve is an extrapolation of transition region, assuming constant $\Delta C_{p}$ during the unfolding transition (Figure 1E). The relationship between $T_{s}, T_{h}$ and $\Delta G\left(T_{s}-T_{h}=\Delta G_{s} / \Delta C_{p}\right)$ is presented in Figure $1 \mathrm{~F}$. Thermodynamic parameters obtained from the analysis of thermal denaturation data are listed in Table 1. All raw data are available as Underlying data ${ }^{18}$.
Chemical induced unfolding monitored by fluorescence There are six Trp residues in hAR, out of which four are part of the hydrophobic active site pocket in the core of the $\beta$-barrel, and two are buried in alpha-helices surrounding the barrel. Their fluorescence provided a global signal of change in the tertiary structure. ANS has been extensively used as a probe for non-native, partially unfolded conformations of the protein. The binding of ANS to hydrophobic regions results in a significant enhancement of ANS fluorescence and a pronounced blue-shift of the $\lambda_{\max }{ }^{19}$.

Fluorescence emission profiles of hAR equilibrated with different concentrations of denaturants are presented in Figure 2 (Figure 2A and Figure 3A for urea and $\mathrm{GuHCl}$, respectively). A plot of $\lambda_{\max }$ against denaturant concentration indicated a cooperative transition from native to unfolded state (Figure 2B and
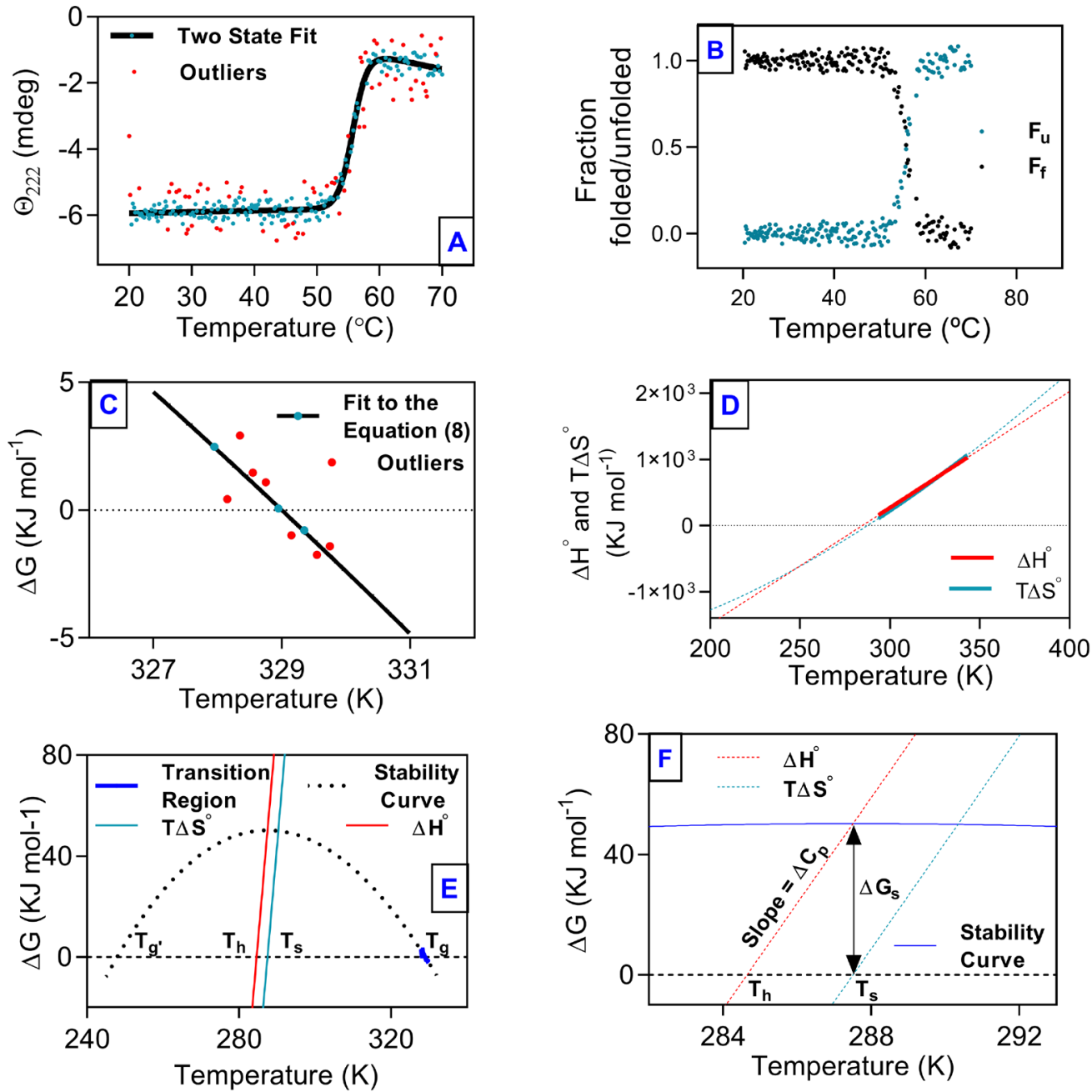

Figure 1. Thermal denaturation studies of human aldose reductase (hAR) monitored by far-UV circular dichroism. (A) Change in ellipticity at $222 \mathrm{~nm}$ plotted as a function of temperature. (B) The fraction of protein folded (black dots) and unfolded (cyan dots) plotted against temperature. (C) The portion of the transition curve used in van't Hoff analysis. (D) Plots of $\Delta \mathrm{H}$ and $\Delta \mathrm{S}$ as a function of temperature. (E) Thermal stability curve of hAR. (F) Triangular relationship among $T_{h}, T_{s}$, and $\Delta G_{s}$. The explanation for $T_{g}, T_{g}, T_{h}$, and $T_{s}$ is given in the text. Dashed lines are extrapolations. The solid lines represent curves fitted to the unfolding transition; filled symbols represent data points from unfolding experiments; and red symbols represent outliers. 

Table 1. Thermodynamic parameters derived from equilibrium unfolding transitions of hAR during thermal denaturation and
Chemical induced unfolding studies using different probes.

\begin{tabular}{|c|c|c|c|c|c|c|c|c|c|}
\hline $\begin{array}{l}\text { Chemical } \\
\text { unfolding }\end{array}$ & Probe & $\begin{array}{l}\Delta \mathrm{G}_{(\mathrm{N}-1)} \\
\left(\mathrm{KJ} \mathrm{mol}^{-1}\right)\end{array}$ & $\begin{array}{l}\Delta G_{(I-U)} \\
\left(\mathrm{KJ}^{\text {mol-1) }}\right)\end{array}$ & $\begin{array}{l}\mathrm{m}_{\left(N^{-1)}\right)} \\
\left(\mathrm{KJ}^{-1} \mathrm{~mol}^{-1} \mathrm{M}^{-1}\right)\end{array}$ & $\begin{array}{l}m_{(I-U)} \\
\left(K^{\prime} \mathrm{mol}^{-1} \mathrm{M}^{-1}\right)\end{array}$ & $\begin{array}{l}C_{m(N-1)} \\
(M)\end{array}$ & $\begin{array}{l}C_{\text {m(l-U) }} \\
\text { (M) }\end{array}$ & & \\
\hline & $\mathrm{GuHCl}\left[\mathrm{F}_{314}\right]$ & $9.47 \pm 1.69$ & $58.34 \pm 1.14$ & $48.34 \pm 7.69$ & $23.56 \pm 0.46$ & 0.16 & 2.48 & & \\
\hline & GuHCl-ANS $\left[F_{480}\right]$ & $16.48 \pm 0.54$ & $57.26 \pm 3.33$ & $38.99 \pm 1.15$ & $22.38 \pm 1.29$ & 0.42 & 2.56 & & \\
\hline & Urea $\left[F_{314}\right]$ & $30.88 \pm 4.47$ & $35.04 \pm 4.16$ & $13.11 \pm 2.01$ & $7.99 \pm 0.84$ & 2.35 & 4.49 & & \\
\hline & Urea-ANS $\left[\mathrm{F}_{480}\right]$ & $28.61 \pm 2.39$ & $38.6 \pm 2.14$ & $12.1 \pm 1.13$ & $8.95 \pm 0.46$ & 2.36 & 4.32 & & \\
\hline & $\mathrm{GuHCl}\left[\Theta_{219}\right]$ & $13.68 \pm 5.78$ & $34.13 \pm 3.75$ & $32.17 \pm 11.63$ & $14.9 \pm 1.58$ & 0.43 & 2.29 & & \\
\hline & Urea $\left[\Theta_{221.8}\right]$ & $30.53 \pm 6.16$ & $24.43 \pm 6.25$ & $14.12 \pm 3.03$ & $5.99 \pm 1.30$ & 2.16 & 4.08 & & \\
\hline \multirow[t]{2}{*}{$\begin{array}{l}\text { Thermal } \\
\text { denaturation }\end{array}$} & Probe & $\begin{array}{l}\Delta \mathrm{G}_{\mathrm{u}} \\
\left(\mathrm{KJ} \mathrm{mol}^{-1}\right)\end{array}$ & $\begin{array}{l}T_{g} \\
(K)\end{array}$ & $\begin{array}{l}\Delta \mathrm{C}_{\mathrm{j}} \\
\left(\mathrm{KJ} \mathrm{mol}^{-1} \mathrm{~K}^{-1}\right)\end{array}$ & $\begin{array}{l}\Delta \mathrm{H}_{\mathrm{g}} \\
\left(\mathrm{KJ} \mathrm{mol}^{-1}\right)\end{array}$ & $\begin{array}{l}\Delta \mathbf{S}_{\mathrm{m}} \\
\left(\mathrm{KJ} \mathrm{mol}^{-1}\right)\end{array}$ & $\begin{array}{l}T_{g} \\
(K)\end{array}$ & $\begin{array}{l}T_{h} \\
(K)\end{array}$ & $\begin{array}{l}T_{s} \\
(K)\end{array}$ \\
\hline & Temperature $\left[\Theta_{222}\right]$ & 50.25 & $329 \pm 0.01$ & 17.57 & $779.20 \pm 15.36$ & 2.37 & 248 & 284.65 & 287.51 \\
\hline
\end{tabular}

Figure $3 \mathrm{~B}$ for urea and $\mathrm{GuHCl}$, respectively). In the case of ANS fluorescence, a significant blue-shift of around 20 $\mathrm{nm}$ and $10 \mathrm{~nm}$ from the native to the intermediate state was observed for urea and $\mathrm{GuHCl}$, respectively (Figure 2B2 and Figure 3B2 for urea and $\mathrm{GuHCl}$, respectively).

A plot of $I_{\max }$ against denaturant concentration indicated the presence of an intermediate during unfolding transition (Figure $2 \mathrm{C}$ and Figure $3 \mathrm{C}$ for urea and $\mathrm{GuHCl}$, respectively). $I_{\max }$ in case of ANS fluorescence fits satisfactorily based on the three-state model (Figure 2C2 and Figure 3C2 for urea and $\mathrm{GuHCl}$, respectively). For both urea and $\mathrm{GuHCl}$ induced unfolding, Trp fluorescence emission intensity at $314 \mathrm{~nm}$ fits satisfactorily to the three-state model. In the case of ANS fluorescence, both $I_{\max }$ and fluorescence emission intensity at $480 \mathrm{~nm}$ fit equally well based on three-state model. Thus, Trp fluorescence emission intensity at $314 \mathrm{~nm}$ and ANS fluorescence emission intensity at $480 \mathrm{~nm}$ were analyzed based on the three-state model to evaluate the thermodynamic stability of hAR (Figure 2D and Figure 3D for urea and $\mathrm{GuHCl}$, respectively). The thermodynamic parameters obtained from the fittings are listed in Table 1. Trp and ANS fluorescence demonstrate the presence of an intermediate state populated at 3.5-4.0 $\mathrm{M}$ and $0.7-2 \mathrm{M}$ urea and $\mathrm{GuHCl}$ concentration, respectively, apart from the native and unfolded states (Figure 2E and Figure $3 \mathrm{E}$ for urea and $\mathrm{GuHCl}$, respectively).

\section{Chemical induced unfolding monitored by far-UV CD}

Unfolding profiles of hAR equilibrated at different denaturant concentrations monitored by far-UV $\mathrm{CD}$ are presented in Figure $4 \mathrm{~A} 1$ and $4 \mathrm{~A} 2$ for $\mathrm{GuHCl}$ and urea, respectively. The thermodynamic stability of hAR was determined based on the three-state model by plotting the change in ellipticity at 219/222 $\mathrm{nm}$ as a function of denaturant concentration (Figure 4B1 and 4B2 for $\mathrm{GuHCl}$ and urea, respectively). The transition determined by far-UV CD detected intermediate state at similar concentrations of denaturant as interrogated by fluorescence spectroscopy. Far-UV CD profiles clearly distinguish three states (Figure 4C1 and 4C2 for $\mathrm{GuHCl}$ and urea, respectively). Thermodynamic parameters derived from far-UV CD data are listed in Table 1.

\section{Discussion}

The intermediate state with enhanced ANS fluorescence and significant blue shift of $\lambda_{\max }$ pointed to an intermediate state with 'molten like' nature during the chemical-induced unfolding of hAR. Far-UV CD studies strongly suggest that the intermediate state retains significant secondary structure during urea- and $\mathrm{GuHCl}$-induced unfolding.

During chemical induced unfolding, hAR unfolds through an intermediate state, which is absent during thermal denaturation. Moderate concentration of denaturant is known to stabilize native or intermediate state ${ }^{20}$. The absence of such a stabilizing agent may be the reason that we could not detect the intermediate state during thermal denaturation.

In all three probes used in studying unfolding, the value of $\Delta G_{(N-I)}$ obtained is $\sim 30 \mathrm{~kJ} \mathrm{~mol}^{-1}$ and $\sim 15 \mathrm{~kJ} \mathrm{~mol}^{-1}$ for ureaand $\mathrm{GuHCl}$-induced unfolding, respectively while a $\Delta G_{s}$ of $\sim 70 \mathrm{~kJ} \mathrm{~mol}^{-1}$ is almost same for both denaturants (Table 1). Thus, while urea seems to stabilize the native state with respect to the intermediate state, $\mathrm{GuHCl}$ seems to stabilize the intermediate state with respect to the native state.

Small molecules change the free energy landscape of protein upon binding by selectively stabilizing native or intermediate/unfolded state $^{21}$. The difference in the value of $\Delta G_{s}$ obtained from thermal denaturation and chemical-induced unfolding is $\sim 20 \mathrm{~kJ} \mathrm{~mol}^{-1}$ (Table 1), which is most likely due to free energy of stabilization and destabilization by urea and $\mathrm{GuHCl}$, respectively.

Values of $\Delta G_{(N-I)}$ obtained from the analysis of ANS fluorescence data are 16.48 and $28.61 \mathrm{~kJ} \mathrm{~mol}^{-1}$ for $\mathrm{GuHCl}$ and urea, respectively (Table 1), which indicates that a steep energy barrier does not separate intermediate state from the native 

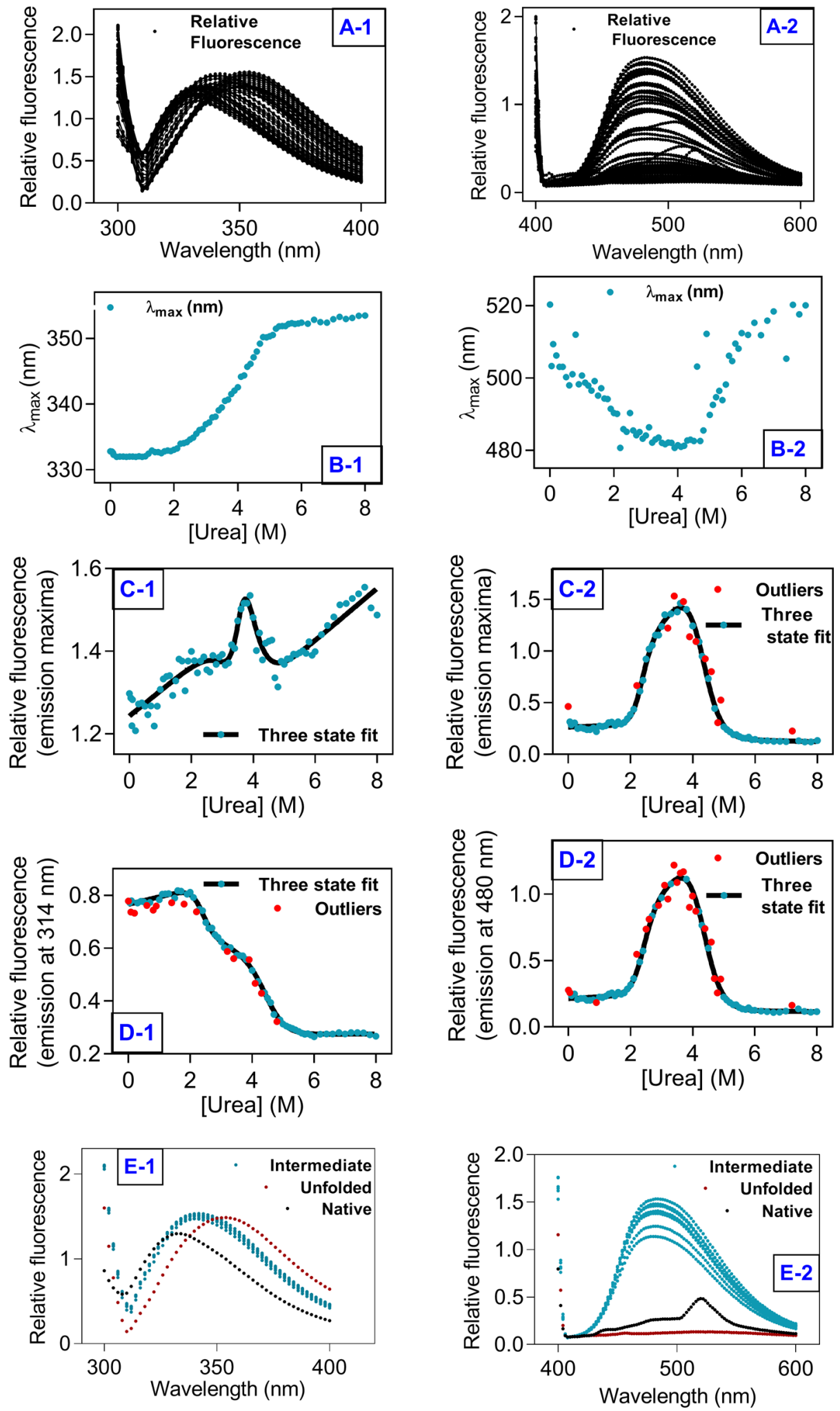

Figure 2. Urea induced unfolding studies of human aldose reductase (hAR)monitored by fluorescence. (A1) Trp fluorescence scans and (A2) ANS fluorescence scans for all the samples. (B1) $\lambda_{\max }$ (Trp fluorescence) and (B2) $\lambda_{\max }$ (ANS fluorescence) against [urea]. (C1) $I_{\max }$ (Trp fluorescence) and (C2) $I_{\max }$ (ANS fluorescence) against [urea]. (D1) $I_{295 / 314}$ (Trp fluorescence) and (D2) $I_{370 / 480}$ (ANS fluorescence) against [urea]. (E1) Trp fluorescence and (E2) ANS fluorescence of samples in native (black), intermediate (cyan), and unfolded state (red) Solid lines represent curves fitted to the unfolding transitions; filled symbols represent data points from unfolding experiments; red symbols represent outliers. 

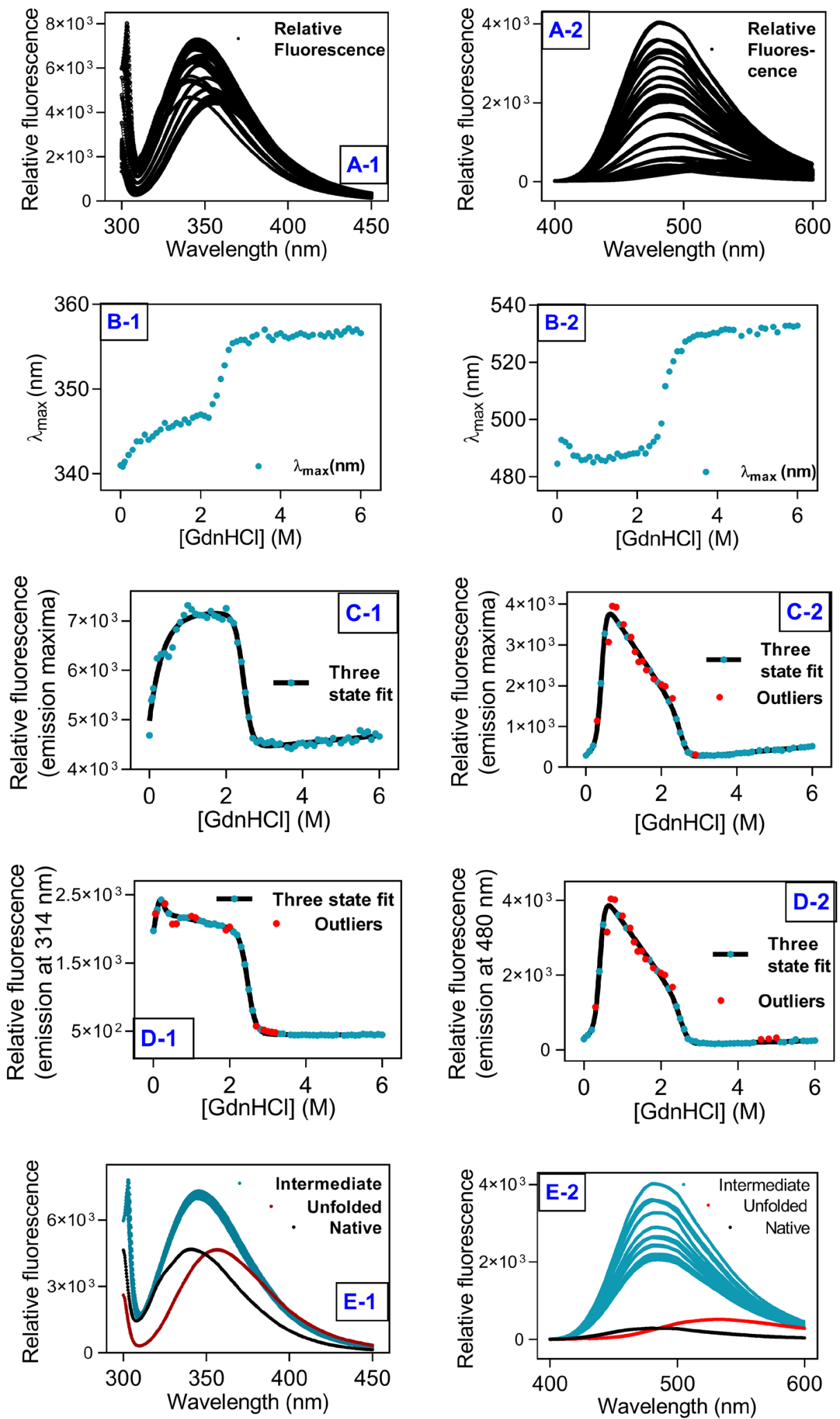

Figure 3. GuHCl-induced unfolding studies of human aldose reductase (hAR)monitored by fluorescence. (A1) Trp fluorescence scans and (A2) ANS fluorescence scans. (B1) $\lambda_{\text {max }}$ (Trp fluorescence) and (B2) $\lambda_{\text {max }}$ (ANS fluorescence) against [GuHCl]. (C1) $I_{\text {max }}$ (Trp fluorescence) and (C2) $I_{\max }$ (ANS fluorescence) against [GuHCl]. (D1) $I_{295 / 314}$ (Trp fluorescence) and (D2) $I_{370 / 480}$ (ANS fluorescence) against [GuHCI]. (E1) Trp fluorescence and (E2) ANS fluorescence of samples in native (black), intermediate (cyan), and unfolded state (red). Solid lines represent curves fitted to the unfolding transitions; filled symbols represent data points from unfolding experiments; red symbols represent outliers. 

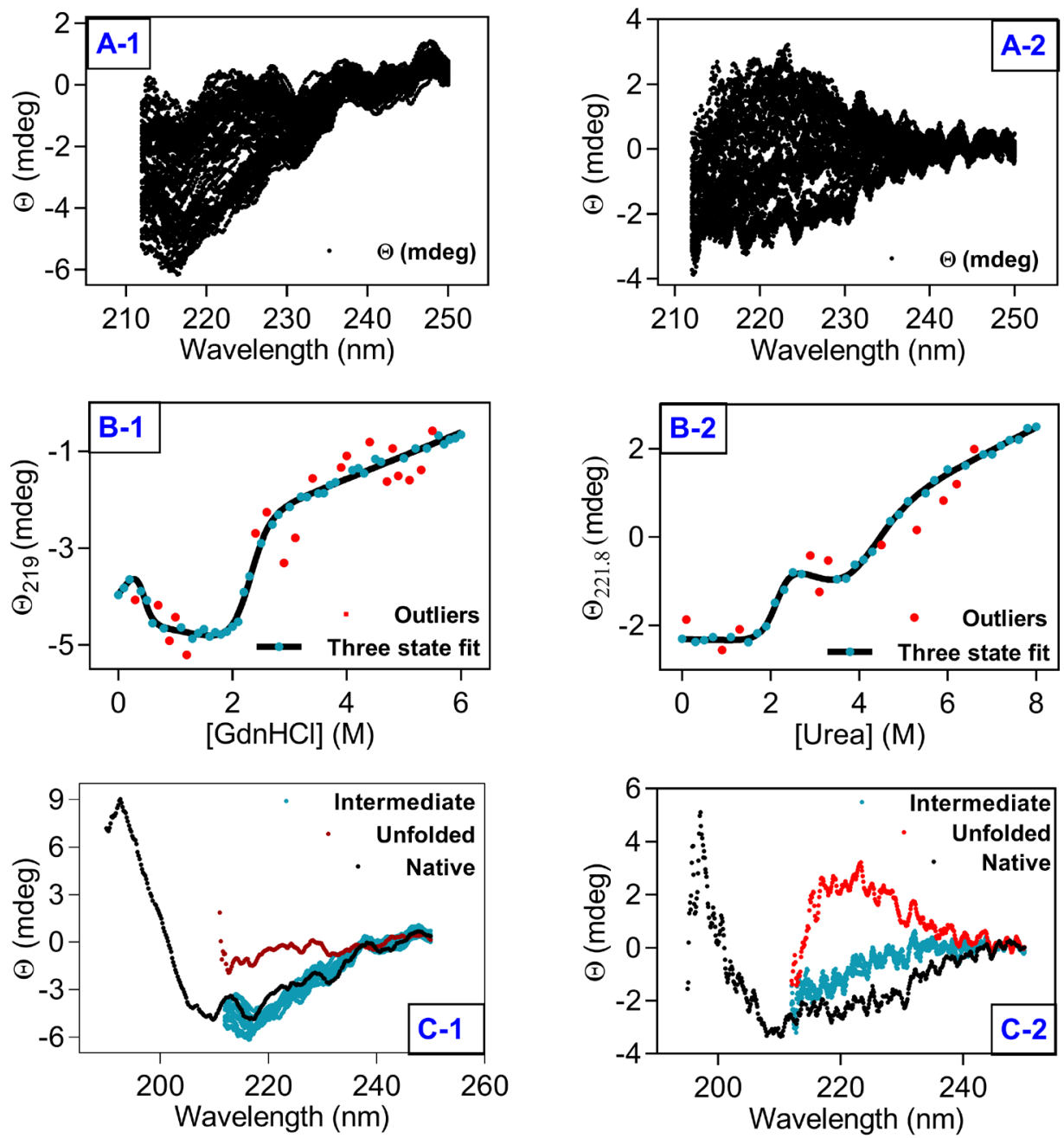

Figure 4. GuHCl/urea induced unfolding studies of human aldose reductase (hAR)monitored by far-UV circular dichroism (CD). (A1) far-UV CD scans recorded for GuHCl and (A2) far-UV CD scans recorded for urea for all the samples. (B1) change in ellipticity at 219 $\mathrm{nm}$ against [GuHCl] and (B2) change in ellipticity at $221.8 \mathrm{~nm}$ against [urea]. (C) CD spectra of samples in native (black), intermediate (cyan), and unfolded state (red) for $(\mathbf{C 1}) \mathrm{GuHCl}$ and $(\mathbf{C 2})$ urea, respectively. The solid lines represent curves fitted to the unfolding transitions; filled symbols represent data points from unfolding experiments; red symbols represent outliers in data fitting.

state. Values for $\Delta G_{(I-U)}$ obtained from ANS fluorescence are 57.26 and $38.6 \mathrm{~kJ} \mathrm{~mol}^{-1}$ for $\mathrm{GuHCl}$ and urea, respectively (Table 1), which indicates that the intermediate state is separated from unfolded state by a high energy barrier. Thus, the intermediate state of hAR is close to its native state, which makes it functionally more relevant. These studies are essential to access the effect of other physiological relevant molecules on hAR stability ${ }^{22}$. Protein stability of hAR in the cellular environment under hyperglycemia-induced cellular stress conditions has to be studied to aid rational drug design ${ }^{23}$.

In summary, equilibrium unfolding studies of hAR have led us to discover that hAR unfolds through an intermediate state, which is close to the native state, and might have physiological relevance under hyperglycemic conditions in diabetes.

\section{Data availability}

Underlying data

Figshare: data_f1000_hAR_unfolding.zip. https://doi.org/ 10.6084/m9.figshare.8001998.v1 ${ }^{18}$.

This project contains raw data for thermal denaturation and chemical induced unfolding studies on human aldose reductase.

Data are available under the terms of the Creative Commons Attribution 4.0 International license (CC-BY 4.0). 


\section{Acknowledgments}

We acknowledge Dr. Alberto Podjarny (Department of Integrated Structural Biology, Institut de Génétique et de Biologie Moléculaire et Cellulaire, CNRS, INSERM, France.) for hAR plasmid as a kind gift, Dr. Yogendra Sharma, at CSIR-CCMB, Hyderabad and Chairperson, Department of Biotechnology, Panjab University, for helping us in spectroscopic data collection. Gurprit acknowledges research fellowship from UGC, Govt. Of India (UGC science JRF).
1. Penning TM: The aldo-keto reductases (AKRs): Overview. Chem Biol Interact. 2015; 234: 236-246.

PubMed Abstract | Publisher Full Text | Free Full Text

2. Brownlee M: The pathobiology of diabetic complications: a unifying mechanism. Diabetes. 2005; 54(6): 1615-1625. PubMed Abstract | Publisher Full Text

3. Yan LJ: Redox imbalance stress in diabetes mellitus: Role of the polyol pathway. Animal Model Exp Med. 2018; 1(1): 7-13. PubMed Abstract | Publisher Full Text | Free Full Text

4. Maccari R, Ottanà R: Targeting aldose reductase for the treatment of diabetes complications and inflammatory diseases: new insights and future directions. J Med Chem. 2015; 58(5): 2047-2067. PubMed Abstract | Publisher Full Text

5. Howard EI, Sanishvili R, Cachau RE, et al.: Ultrahigh resolution drug design I: details of interactions in human aldose reductase-inhibitor complex at $0.66 \mathrm{~A}$. Proteins. 2004; 55(4): 792-804. PubMed Abstract | Publisher Full Text

6. Sotriffer CA, Krämer O, Klebe G: Probing flexibility and "induced-fit" phenomena in aldose reductase by comparative crystal structure analysis and molecular dynamics simulations. Proteins. 2004; 56(1): 52-66. PubMed Abstract | Publisher Full Text

7. Rechlin C, Scheer F, Terwesten F, et al:: Price for Opening the Transient Specificity Pocket in Human Aldose Reductase upon Ligand Binding: Structural, Thermodynamic, Kinetic, and Computational Analysis. ACS Chem Biol. 2017; 12(5): 1397-1415. PubMed Abstract | Publisher Full Text

8. Dill KA, MacCallum JL: The protein-folding problem, $\mathbf{5 0}$ years on. Science. 2012 338(6110): 1042-6.

PubMed Abstract | Publisher Full Text

9. Judy E, Kishore N: A look back at the molten globule state of proteins: thermodynamic aspects. Biophys Rev. 2019; 11(3): 365-375. PubMed Abstract | Publisher Full Text | Free Full Text

10. Englander $\mathrm{S}$, Mayne L: The case for defined protein folding pathways. Proc Nat Acad Sci USA. 2017; 114(31): 8253-8258

PubMed Abstract | Publisher Full Text | Free Full Text

11. Gruebele M, Dave K, Sukenik S: Globular Protein Folding In Vitro and In Vivo. Annu Rev Biophys. 2016; 45(1): 233-251. PubMed Abstract | Publisher Full Text

12. Cremades $N$, Sancho J, Freire $E$ : The native-state ensemble of proteins provides clues for folding, misfolding and function. Trends Biochem Sci. 2006; 31(9):
494-496.

PubMed Abstract | Publisher Full Tex

13. Balendiran GK, Sawaya MR, Schwarz FP, et al:: The role of Cys-298 in aldose reductase function. J Biol Chem. 2011; 286(8): 6336-6344.

PubMed Abstract | Publisher Full Text | Free Full Text

14. Myers JK, Pac CN, Scholtz JM: Denaturant $\boldsymbol{m}$ values and heat capacity changes: relation to changes in accessible surface areas of protein unfolding. Protein Sci. 1995; 4(10): 2138-2148.

PubMed Abstract | Publisher Full Text | Free Full Text

15. Estrada J, Bernadó P, Blackledge M, et al:: ProtSA: a web application for calculating sequence specific protein solvent accessibilities in the unfolded ensemble. BMC Bioinformatics. 2009: 10: 104 PubMed Abstract | Publisher Full Text | Free Full Text

16. Grimsley GR, Trevino SR, Thurlkill RL, et al.: Determining the conformational stability of a protein from urea and thermal unfolding curves. Curr Protoc Protein Sci. 2013; Chapter 28: Unit28.4 PubMed Abstract | Publisher Full Text

17. Becktel WJ, Schellman JA: Protein stability curves. Biopolymers. 1987; 26(11): 1859-1877.

PubMed Abstract | Publisher Full Text

18. Sekhon G, Singh R: data_f1000_hAR_unfolding.zip. figshare. Dataset. 2019. http://www.doi.org/10.6084/m9.figshare.8001998.v1

19. Cattoni DI, Kaufman SB, González Flecha FL: Kinetics and thermodynamics of the interaction of 1-anilino-naphthalene-8-sulfonate with proteins. Biochim Biophys Acta. 2009; 1794(11): 1700-1708.

PubMed Abstract | Publisher Full Text

20. Bhuyan AK: Protein stabilization by urea and guanidine hydrochloride. Biochemistry. 2002; 41(45): 13386-13394. PubMed Abstract | Publisher Full Text

21. Street TO, Bolen DW, Rose GD: A molecular mechanism for osmolyte-induced protein stability. Proc Natl Acad Sci U S A. 2006; 103(38): 13997-4002. PubMed Abstract | Publisher Full Text | Free Full Text

22. Kabir A, Honda RP, Kamatari YO, et al.: Effects of ligand binding on the stability of aldo-keto reductases: Implications for stabilizer or destabilizer chaperones. Protein Sci. 2016; 25(12): 2132-2141. PubMed Abstract | Publisher Full Text | Free Full Text

23. Brylski O, Ebbinghaus S, Mueller JW: Melting Down Protein Stability: PAPS Synthase 2 in Patients and in a Cellular Environment. Front Mol Biosci. 2019; 6: 31. PubMed Abstract | Publisher Full Text | Free Full Text 


\section{Open Peer Review}

\section{Current Peer Review Status: $\checkmark$ ? ?}

\section{Version 2}

Reviewer Report 14 November 2019

https://doi.org/10.5256/f1000research.23232.r56209

(C) 2019 Yan Y. This is an open access peer review report distributed under the terms of the Creative Commons Attribution License, which permits unrestricted use, distribution, and reproduction in any medium, provided the original work is properly cited.

\section{Yong-Bin Yan ic}

State Key Laboratory of Membrane Biology, School of Life Sciences, Tsinghua University, Beijing, China

I am sorry for that I can not approve the revised versioon since the authors did not address most of my concerns raised during last round of review, particular of the change in enzymatic activity, the validity of the calculations and the effect of pathological stresses.

Competing Interests: No competing interests were disclosed.

Reviewer Expertise: Biophysics, biochemistry, cell biology, enzymology, spectroscopy, protein folding,misfolding and aggregation, aggregation diseases, proteostasis, cataract, mRNA decay, deadenylation, translation regulation

I confirm that I have read this submission and believe that I have an appropriate level of expertise to confirm that it is of an acceptable scientific standard, however I have significant reservations, as outlined above.

Reviewer Report 06 November 2019

https://doi.org/10.5256/f1000research.23232.r56208

(C) 2019 Mueller J. This is an open access peer review report distributed under the terms of the Creative Commons Attribution License, which permits unrestricted use, distribution, and reproduction in any medium, provided the original work is properly cited.

Jonathan W. Mueller

Institute of Metabolism and Systems Research (IMSR), University of Birmingham, Birmingham, UK

The authors seem to have carefully addressed all points raised. 
Competing Interests: No competing interests were disclosed.

I confirm that I have read this submission and believe that I have an appropriate level of expertise to confirm that it is of an acceptable scientific standard.

\section{Version 1}

Reviewer Report 01 August 2019

https://doi.org/10.5256/f1000research.20788.r51586

(C) 2019 Yan Y. This is an open access peer review report distributed under the terms of the Creative Commons Attribution License, which permits unrestricted use, distribution, and reproduction in any medium, provided the original work is properly cited.

\section{Yong-Bin Yan}

State Key Laboratory of Membrane Biology, School of Life Sciences, Tsinghua University, Beijing, China

In this research, the authors studied the equilibrium unfolding pathway of human aldose reductase (hAR) by spectroscopic methods. Although this pure unfolding study may provide information of how hAR unfolds, the underlying physiological relevance is unclear. Furthermore, the present study needs to be improved in the quality of the data and interpretation.

During my preparation of the comments, Professor Uversky and Professor Mueller have published their excellent comments and suggestions. I agree with those points raised in their reports. Below are some additional comments that could be considered by the authors to improve their work.

1. Although the authors have mentioned the importance of hAR in the Abstract and Introduction, especially for that it is an enzyme functions under osmotic stresses, it is unclear for the physiological relevance of the information obtained here using heat and chemical denaturants. I suggest the authors considered the physiologically relevant factors such as osmotic stress in their revised or future work.

2. hAR is an enzyme. I suggest the authors monitor the activity of the enzyme during unfolding to provide information regarding the local structural changes around the active site.

3. I am not convinced by the calculations of the thermodynamic parameters. The equations listed in the manuscript are derived from reverse folding processes. However, the authors did not show that the folding of hAR was reversible or not.

4. The authors concluded that the thermal unfolding of hAR was a two-state process by far-UV CD spectra analysis. However, only one method/probe is difficult for the definition of a twostate transition. It's better to study the transition with two or more probes and pure two- 
state transition will give similar transitions as well as thermodynamic parameters for all probes.

5. The authors concluded that hAR undergo a three-state transition during unfolding by chemical denaturants. The present data could not support this statement. The emission maximum wavelength of the Trp fluorescence revealed no populations of any intermediates. An intermediate seems to populate at low denaturant concentrations when observed by Trp fluorescence intensity. However, intrinsic fluorescence intensity is easily affected by numerous environmental factors and is not as reliable as the emission maximum wavelength. Yes, there is an obvious increase in ANS fluorescence. Previously Turoverov and his co-authors have shown that the appearance of off-pathway aggregates, in some cases, can enhance ANS fluorescence. ${ }^{1}$ It is necessary to avoid the misleading interpretation by identifying the potential intermediate(s) via more methods.

6. It is unclear whether all the solid lines are fitted data or not. Moreover, it is better to provide the residuals to facilitate the readers to evaluate whether the fitting is appropriate.

7. In Figure 3, the ANS profiles seem to comprise more than one state and are likely to be the sum of at least two states centered at around 1 and $2 \mathrm{M} \mathrm{GdnHCl}$ ?

8. CD signals are recommended to report in molar ellipticities. The quality of the far-UV CD spectra is not enough. High concentration of denaturants may affect the signals at low wavelengths, generally below $210 \mathrm{~nm}$. However, the low signal-to-noise seems to be affected by other factors. The authors can try to adjust the measuring parameters such as the slit width and number of repetitions. Furthermore, the authors mentioned that all chemicals were Sigma reagent grade. To my experience, $\mathrm{GdnHCl}$ with an ultrapure grade will produce much better signals that the lower grades. Note that the impurities or contaminated solvents will greatly affect spectroscopic measurements. Before spectroscopic measurements, the samples should be filtered and degassed. Detailed guidelines of spectroscopic measurements can be found in the paper by Kelly et al. ${ }^{2}$

9. The units of the fluorescence intensities in Figures 2 and 3 are quite different. Are these data normalized by the same method? Furthermore, the spectra of $\mathrm{N}$ in panels $\mathrm{E}-2$ should refer to the state in the absence of denaturant. Why the spectrum of $\mathrm{N}$ in Figure $2 \mathrm{E}-2$ is different from that in Figure 3E-2? To me, the spectrum of N in Figure $2 \mathrm{E}-2$ is strange. Please verify that the solutions are not affected by contaminants.

\section{References}

1. Povarova OI, Kuznetsova IM, Turoverov KK: Differences in the pathways of proteins unfolding induced by urea and guanidine hydrochloride: molten globule state and aggregates.PLoS One. 2010; 5 (11): e15035 PubMed Abstract | Publisher Full Text

2. Kelly SM, Jess TJ, Price NC: How to study proteins by circular dichroism.Biochim Biophys Acta. 2005; 1751 (2): 119-39 PubMed Abstract | Publisher Full Text

\section{Is the work clearly and accurately presented and does it cite the current literature?}


Partly

Is the study design appropriate and is the work technically sound?

Partly

Are sufficient details of methods and analysis provided to allow replication by others? Yes

If applicable, is the statistical analysis and its interpretation appropriate?

Not applicable

Are all the source data underlying the results available to ensure full reproducibility? Yes

Are the conclusions drawn adequately supported by the results?

Partly

Competing Interests: No competing interests were disclosed.

Reviewer Expertise: Biophysics, biochemistry, cell biology, enzymology, spectroscopy, protein folding,misfolding and aggregation, aggregation diseases, proteostasis, cataract, mRNA decay, deadenylation, translation regulation

I confirm that I have read this submission and believe that I have an appropriate level of expertise to confirm that it is of an acceptable scientific standard, however I have significant reservations, as outlined above.

Reviewer Report 08 July 2019

https://doi.org/10.5256/f1000research.20788.r50821

(C) 2019 Uversky V. This is an open access peer review report distributed under the terms of the Creative Commons Attribution License, which permits unrestricted use, distribution, and reproduction in any medium, provided the original work is properly cited.

Vladimir Uversky

Department of Molecular Medicine, College of Medicine, University of South Florida, Tampa, FL, USA

In this manuscript, Gurprit Sekhon and Ranvir Singh describe the results of the equilibrium unfolding of human aldose reductase. The authors conclude that urea- and GuHCL-induced unfolding of this protein is characterized by the presence of partially folded intermediate. This is an interesting study with some potential. However, additional experiments are needed to provide more evidence for the existence of an intermediate state and also to provide better description of the structural properties of this protein.

1. The authors are encouraged to add near-UV CD spectroscopy to the arsenal of techniques 
utilized in their study. This will give very important information on the effect of denaturants on the tertiary structure of a protein. In fact, combined use of near- and far-UV spectroscopy is the accepted practice in studies on the conformational stability of proteins.

2. Quality of the reported far-UV CD spectra is very low. Spectra are very noisy and their utilization for the analysis of the effects of urea and $\mathrm{GuHCl}$ on secondary structure of human aldose reductase is questionable. The authors have to change settings to generate more reliable and less noisy spectra. Probably, protein concentrations should be increased too.

3. Far-UV CD spectra of completely unfolded forms induced by high concentrations of urea and $\mathrm{GuHCl}$ are very different, suggesting that these unfolded forms are not similar. Why?

4. Compactness of an intermediate state should be evaluated. This can be done by a whole host of hydrodynamic techniques.

5. The authors should make sure that the protein does not aggregate at the conditions promoting formation of a partially unfolded intermediate. This can be done by simple light scattering experiments.

6. Data shown in Figure 3 suggest that very low $\mathrm{GuHCl}$ concentrations cause very noticeable changes in some of the analyzed parameters. Similar behavior was described previously ${ }^{1}$ and was attributed to the aggregation of partially unfolded species. This phenomenon should be discussed.

7. The presence of partially folded intermediates can be visualized using "phase diagram" method described in previous work by Kuznetsova et al. ${ }^{2}$ The authors are encouraged to use this approach for the analysis of their data.

8. The authors are encouraged to reconsider the use of terms "denatured/denaturation" and "unfolded/unfolding". Typically, unfolding is attributed to the process resulting in the formation of coil-like conformation, whereas denaturation is referred to the elimination of functional tertiary structure. Obviously, these terms are not equivalent - molten globule is denatured, but is not unfolded. Furthermore, although temperature increase typically causes melting of a protein tertiary structure, temperature-denatured species are often rather compact and preserve high levels of secondary structure.

9. The manuscript contains some linguistic issues and errors and definitely needs editing.

\section{References}

1. Povarova OI, Kuznetsova IM, Turoverov KK: Differences in the pathways of proteins unfolding induced by urea and guanidine hydrochloride: molten globule state and aggregates.PLoS One. 2010; 5 (11): e15035 PubMed Abstract | Publisher Full Text

2. Kuznetsova IM, Turoverov KK, Uversky VN: Use of the phase diagram method to analyze the protein unfolding-refolding reactions: fishing out the. J Proteome Res. 3 (3): 485-94 PubMed Abstract 
Is the work clearly and accurately presented and does it cite the current literature? Partly

Is the study design appropriate and is the work technically sound?

Partly

Are sufficient details of methods and analysis provided to allow replication by others? Yes

If applicable, is the statistical analysis and its interpretation appropriate? Yes

Are all the source data underlying the results available to ensure full reproducibility? Yes

Are the conclusions drawn adequately supported by the results? Partly

Competing Interests: No competing interests were disclosed.

Reviewer Expertise: Protein physics; protein folding; partially folded proteins; folding intermediates; protein misfolding' protein aggregation; conformational diseases; intrinsically disordered proteins

I confirm that I have read this submission and believe that I have an appropriate level of expertise to confirm that it is of an acceptable scientific standard, however I have significant reservations, as outlined above.

Reviewer Report 24 June 2019

https://doi.org/10.5256/f1000research.20788.r50315

(C) 2019 Mueller J. This is an open access peer review report distributed under the terms of the Creative Commons Attribution License, which permits unrestricted use, distribution, and reproduction in any medium, provided the original work is properly cited.

Jonathan W. Mueller

Institute of Metabolism and Systems Research (IMSR), University of Birmingham, Birmingham, UK

Drs Sekhon and Singh have presented an in-vitro study "Human aldose reductase unfolds through an intermediate" to F1000Research to be considered for indexing. Foremost, the authors should describe the newly described intermediate more with respect to its potential physiological relevance to stress the relevance of this study.

Please remove "ultra" from any description for protein crystal structures, but add the actual resolution of that structure, $0.66 \mathrm{~A}$ from Ref. 5, and explain what additional features were derived 
from these, compared to average crystal structures.

"Understanding the capability of a polypeptide..." - this sentence only has limited linkage to the sentence beforehand and should be deleted. Instead, novel concepts of protein folding and stability should be briefly covered. ${ }^{1,2}$

Figure 1:

A) it is not clear what the blue and red dots mean.

B) Please do not use green and red as colors.

Figure 2:

$A+B)$ Please label the different graphs within the diagrams.

The manuscript needs careful copy-editing.

\section{References}

1. Pastore A, Martin SR, Temussi PA: Generalized View of Protein Folding: In Medio Stat Virtus.J Am Chem Soc. 2019; 141 (6): 2194-2200 PubMed Abstract | Publisher Full Text

2. Brylski O, Ebbinghaus S, Mueller JW: Melting Down Protein Stability: PAPS Synthase 2 in Patients and in a Cellular Environment.Front Mol Biosci. 2019; 6: 31 PubMed Abstract | Publisher Full Text

Is the work clearly and accurately presented and does it cite the current literature? Partly

Is the study design appropriate and is the work technically sound?

Yes

Are sufficient details of methods and analysis provided to allow replication by others? Yes

If applicable, is the statistical analysis and its interpretation appropriate? Yes

Are all the source data underlying the results available to ensure full reproducibility? Partly

Are the conclusions drawn adequately supported by the results? Yes

Competing Interests: No competing interests were disclosed.

I confirm that I have read this submission and believe that I have an appropriate level of expertise to confirm that it is of an acceptable scientific standard, however I have significant reservations, as outlined above. 
The benefits of publishing with F1000Research:

- Your article is published within days, with no editorial bias

- You can publish traditional articles, null/negative results, case reports, data notes and more

- The peer review process is transparent and collaborative

- Your article is indexed in PubMed after passing peer review

- Dedicated customer support at every stage

For pre-submission enquiries, contact research@f1000.com 